\title{
Protein Deficiency and the Growing Rat Lung. II. Morphometric Analysis and Morphology
}

\author{
MASENDU KALENGA, ${ }^{1}$ STEFAN A. TSCHANZ, AND PETER H. BURRI \\ Institute of Anatomy, Section of Developmental Biology, University of Berne, \\ CH-3000 Berne 9, Switzerland
}

ABSIRACT

\begin{abstract}
Effects of protein deficiency during the whole period of postnatal development and intensive growth were studied in the rat lung parenchyma. Dams received a low protein diet as follows: early restriction, $8 \%$ casein diet from parturition, and delayed restriction, $12 \%$ then $8 \%$ casein diet from lactation $\mathrm{d} 8$. After weaning (d 21), early restriction and delayed restriction group rats were maintained on the $8 \%$ casein diet until d 49 , wherefrom they were returned to normal food ( $18 \%$ casein) for 11 wk. Lungs were processed for light and electron microscopic morphometry on $\mathrm{d} 21,49$, and 126 . The diffusion capacity of the lung for $\mathrm{O}_{2}\left(\mathrm{DLO}_{2}\right)$ was also determined from the morphologic parameters. Volume and surface densities of the parenchymal components of malnourished rats did not consistently differ from controls. Because of lower lung volumes, absolute values, including $\mathrm{DLO}_{2}$, were all significantly decreased. Further, although lung volume growth was less impaired than body growth and thus deviated from the normal allometric relationship, most morphometric parameters paralleled body weight changes. Visually, we detected minor morphologic alterations at $\mathrm{d} 21$ and 49 , not necessarily reflected by morphometric data. But, importantly, lung parenchyma appeared mature at weaning despite the growth retardation. Normal refeeding resulted in a striking regrowth of the lung parenchyma. Although early restriction rats did not fully catch up in lung volume, most parenchymal parameters and $\mathrm{DLO}_{2}$ were largely restored in both refed groups. (Pediatr Res 37: 789-795, 1995)
\end{abstract}
Abbreviations
Dbo $_{2}$, diffusion capacity for $\mathrm{O}_{2}$ of air-blood tissue barrier
$\mathrm{DeO}_{2}$, diffusion capacity for $\mathrm{O}_{2}$ for erythrocytes
DLO $_{2}$, pulmonary diffusion capacity for $\mathrm{O}_{2}$
DR, delayed restriction in protein
EM, electron microscopy
ER, early restriction in protein
LM, light microscopy
Sa, surface area of the air spaces in the lung
Sc, surface area of the capillaries in the lung
$\mathbf{S}_{\mathbf{V} \text { a }}$, surface density of the air spaces in the parenchyma
$\mathbf{S}_{\mathbf{V} \mathbf{c}}$, surface density of the capillary blood in the parenchyma
$\mathbf{S}_{\mathbf{V e c}}$, surface density of the erythrocytes in the parenchyma
Va, volume of the air spaces in the lung
Vc, volume of the capillary blood in the lung
Vs, volume of the septum in the lung
$\mathbf{V t}$, volume of the tissue in the lung
$\mathbf{V}_{\mathbf{V a}}$, volume density of the air spaces in the parenchyma
$\mathbf{V}_{\mathbf{V}}$, volume density of the capillary blood in the parenchyma
$\mathbf{V}_{\mathbf{V}}$, volume density of the parenchyma in the lung
$\mathrm{V}_{\mathrm{V}_{s}}$, volume density of the septa in the parenchyma
$\mathbf{V}_{\mathbf{V}}$, volume density of the tissue in the parenchyma
W, body weight

Nutritional deficiencies in experimental animals have been associated in various ways with structural alterations of the lung parenchyma (1-9). By far the most common findings are enlargement of the terminal air spaces with reduction of internal surface area and even alveolar wall rupture. This emphysema-like pattern is sometimes termed "nutritional emphysema" (6). Although the rat has been extensively studied in this

Received June 28, 1994; accepted December 12, 1994

Correspondence: Peter H Burri, M.D., Institute of Anatomy, Bühlstrasse 26, Postfach 139, CH-3000, Berne 9, Switzerland.

Supported by grant $3100-36530.92$ from the Swiss National Science Foundation.

${ }^{1}$ M.K. was supported by a fellowship from Nestlé-Nutrition/Switzerland. Present address: University of Louvain, UCL/ENDO 5530, Avenue Hippocrate 55, B-1200 Brussels, Belgium. respect, most investigations were limited to short durations of food restriction, or they concerned weaned rats. As it has been clearly established, the rat lung parenchyma undergoes dramatic structural changes within the first $3 \mathrm{wk}$, i.e. during the period of suckling (10-13). These changes comprise not only a significant growth of the lung, but also the formation of alveoli along with an increase in gas-exchange surface area and a maturation of the parenchymal capillary network. These processes result in a more mature appearance of the parenchyma characterized by thinner septa with a single capillary network. Up to the age of $7 \mathrm{wk}$, tissue mass still markedly augments but to a lesser extent than air space volume. This is due more to cellular hyperplasia than to hypertrophy, and beyond the age of $7 \mathrm{wk}$ the amount of DNA remains almost 
constant (14). All of these processes are susceptible to the deleterious effects of malnutrition.

We have been especially interested by the effects of protein restriction on the rat lung and one of us has found that an early start (i.e. during the neonatal period) more particularly affected lung DNA, connective tissue accumulation and lung mechanics $(15,16)$. In a companion study (17), we have shown that volumes of in situ fixed lungs were markedly decreased in pups and rats restricted in protein from the neonatal period. This was associated with an alteration in the allometric relationship between lung volume and body weight. After $11 \mathrm{wk}$ of refeeding, a striking regrowth in body weights and lung volumes was observed. The allometry of lung volume to body weight was restored. Here, we present the detailed morphometric findings and the morphologic observations obtained in the lungs of these animals.

\section{METHODS}

Nutrition and lung fixation. The methodologic procedures for animal care and nutrition and for lung fixation have been detailed in a companion study (17). In brief, timed pregnant SIVZ50 rats were randomly assigned to one of the experimental groups and allowed normal or protein-restricted food and water ad libitum. Litter size was standardized to eight pups (all males) at lactation $\mathrm{d} 2$. The nutritional protocol and the dietary groups were defined as follows: the ER group was fed an $8 \%$ casein diet from parturition (or postnatal d 1) until d 49; the DR group was given a $12 \%$ casein diet from $\mathrm{d} 8$ to 14 and thereafter fed the $8 \%$ casein diet up to $\mathrm{d} 49$. The offspring started to eat the actual maternal diet before weaning and were kept on it after weaning. Because of a significant variation in body weight among ER rats, two singular groups (i.e. two different litters) had to be considered distinctly from the main ER group and were labeled as large ER at d 21 and small ER group at d 49. From d 49 until the end of the study (d 126), some ER and DR rats were refed with an $18 \%$ casein diet that was given to an age-matched control group throughout the experiment. On d 21, 49, and 126, the lungs were fixed by standard intratracheal instillation of potassium phosphatebuffered glutaraldehyde $(2.5 \% ; \mathrm{pH} 7.4 ; 350$ mosmol) at a constant pressure of $20 \mathrm{~cm} \mathrm{H} \mathrm{H}_{2} \mathrm{O}$ under deep anesthesia. After dissection, the lung volumes were determined by water displacement.

Tissue sampling and processing. Three to four animals per group were selected for lung analysis. The entire lung was embedded in $2 \%$ agar (18) and cut perpendicularly to its longitudinal axis in $2.5-\mathrm{mm}$ thick slices using the tissue slicer described by Michel and Cruz-Orive (19). For the larger lungs of d 126, 2.5-mm slices were alternated with $5.5-\mathrm{mm}$ ones. Thus, from each lung we obtained at least 20 slices of $2.5-\mathrm{mm}$ thickness that were laid flat and aligned for a multiple-step systematic random sampling (20). We sampled two series of a minimum of eight slices each for the LM and EM analysis.

The slices selected for LM evaluation were embedded in paraffin, and a 4- $\mu \mathrm{m}$ thick section was obtained from each slice and stained with hematoxylin-eosin. For EM investi- gation the selected slices were cut longitudinally into strips approximately $2 \mathrm{~mm}$ wide, of which six were sampled and diced into small cubes. A minimum of 10 cubes were randomly sampled, postfixed with $1 \%$ osmium tetroxide, and embedded in epoxy resin (Epon 812; Fluka Chemie AG, Buchs). Five of these blocks were picked at random, and from each of them one ultrathin section was obtained and placed on a 200 mesh copper grid. These specimens were stained with uranyl acetate and lead citrate and examined with a Philips EM-200 (Philips AG, Einhoven). Using the systematic aligned quadrat subsampling (20), from each of the five sections per animal eight micrographs (i.e. 40 micrographs per animal) were recorded on $35-\mathrm{mm}$ film. A positive contact film copy was obtained from the negative and processed for morphometric evaluation.

Morphometric analysis. LM morphometric evaluation was carried out with a Wild M 501 (Leica AG, Heerdrugg) sampling stage microscope at a magnification of $400 \times$ on a projection screen with one single central test point. The specimen was automatically displaced stepwise by $550 \mu \mathrm{m}$ for lungs at d 21 and 49, or by $825 \mu \mathrm{m}$ for lungs at d 126. Each section was scanned entirely while recording the hits on parenchyma (air spaces and interalveolar septa), and on nonparenchyma comprising airways down to respiratory bronchioles, blood vessels larger than $25 \mu \mathrm{m}$ in diameter, and connective tissue septa. Sample size was dimensioned as to allow at least 200 hits for each lung compartment. Hits were counted using the STEPone program (21), which allowed to determine the volume densities of parenchyma $\left(\mathrm{V}_{\mathrm{Vp}}\right)$ and of nomparenchyma.

EM evaluation of the positive contact film copies was performed on a projection screen at a final magnification of $10,200 \times$. Using the coherent multipurpose test system M 168 we determined by point and intersection counting (22) the following parameters in the parenchyma: 1) the volume densities of air spaces $\left(\mathrm{V}_{\mathrm{Va}_{\mathrm{a}}}\right)$, of the tissue $\left(\mathrm{V}_{\mathrm{Vt}_{\mathrm{t}}}\right)$ and of its components (epithelium, endothelium, and interstitium), of the capillary blood $\left(\mathrm{V}_{\mathrm{V}_{\mathrm{c}}}\right)$ and of the septa $\left.\left(\mathrm{V}_{\mathrm{V}_{\mathrm{s}}}\right) ; 2\right)$ the surface densities of air spaces $\left(\mathrm{S}_{\mathrm{Va}}\right)$, of capillaries $\left(\mathrm{S}_{\mathrm{Vc}}\right)$, and of erythrocytes $\left(\mathrm{S}_{\mathrm{Vec}}\right)$. Furthermore, the harmonic mean thickness of the total air-blood barrier (tissue plus plasma) was measured (23).

Morphologic assessment. The LM morphology was studied in paraffin sections and in Epon semithin sections stained with toluidine blue with an Olympus Vanox $\mathrm{S}$ microscope. For EM morphology, we investigated the same sections used for morphometry.

Calculations and statistical analysis. For each morphometric parameter the absolute value in the whole lung was calculated by multiplying its relative value by the respective proportion of parenchyma $\left(\mathrm{V}_{\mathrm{Vp}}\right)$ and by the lung volume. The specific value was computed as the corresponding absolute value per $100 \mathrm{~g}$ body weight. Furthermore, we determined for each animal: 1 ) the arithmetic mean air-blood barrier thickness, 2) the arithmetic mean septal thickness, and 3) the hematocrit. Based on the morphometric model described by Weibel et al. (23), the pulmonary diffusion capacity for oxygen $\left(\mathrm{DLO}_{2}\right)$ was calculated as absolute and specific values. The 
following formulas were used:

$$
\begin{gathered}
1 / \mathrm{DLO}_{2}=1 / \mathrm{Dbo}_{2}+1 / \mathrm{DeO}_{2} ; \\
\mathrm{Dbo}_{2}=\mathrm{Kb} \cdot(\mathrm{Sa}+\mathrm{Sc}) /\left(2 \tau_{\mathrm{hb}}\right),
\end{gathered}
$$

where $\mathrm{K}_{\mathrm{b}}$ is the Krogh diffusion constant that was assumed to be $3.3 \cdot 10^{-8} \mathrm{~cm}^{2} \cdot \mathrm{min}^{-1} \cdot \mathrm{mmHg}^{-1}(23)$;

$$
\mathrm{DeO}_{2}=\Theta_{\mathrm{O}_{2}} \cdot \mathrm{Vc}
$$

where $\Theta_{\mathrm{O} 2}$ is the rate of $\mathrm{O}_{2}$ uptake by the whole blood that was calculated as $7.158 \times$ hematocrit (23).

The results are presented as means \pm 1 SEM of the group. After a one-way analysis of variance, the difference between group means was tested using the Student-Newman-Keul's test for multiple comparisons (cited in Ref. 24). The singular large and small ER rats were compared with the main ER group of the same age using a $t$ test. The significance level was set at $p<0.05$ for the two-tailed tests.

\section{RESULTS}

Findings after protein restriction. The relative data of morphometry of the lung are displayed in Table 1 . It appears that protein restriction did not significantly affect the proportion of the parenchyma in the lung $\left(\mathrm{V}_{\mathrm{v}_{\mathrm{p}}}\right)$ in both our experimental groups. Further, in comparison to age-matched controls no consistent alterations of volume and surface densities of the parenchymal components were detected in malnourished rats neither at weaning nor at $d 49$. Animals of the small ER litter at $\mathrm{d} 49$, however, had significantly lower $\mathrm{V}_{\mathrm{Vt}}(9.1 \% \pm 0.4$ versus $10.8 \% \pm 0.9)$ and a smaller $\mathrm{S}_{\mathrm{Va}}\left(626.6 \pm 41.0 \mathrm{~cm}^{-1}\right.$ versus $853.3 \pm 48.7 \mathrm{~cm}^{-1}$ ) when compared with values of the main ER group in Table 1 .

Table 2 displays the basic animal data and the absolute volumes and surfaces of the lung components. Air-blood barrier thicknesses and absolute $\mathrm{DLO}_{2}$ values are shown in Table 3. The second part of the tables is dedicated to the results obtained in the singular large and small ER rats. These data have to be compared with those of standard ER groups of the corresponding age.

At weaning, protein restriction had resulted in a constant reduction in all volumes and surfaces of the parenchymal components compared with control values. At the tissue com- partment level, the absolute volume of interstitium did not differ between the control and the DR groups, but was significantly decreased in ER rats (control $=0.123 \pm 0.013 \mathrm{~cm}^{3}$, $\mathrm{DR}=0.107 \pm 0.005 \mathrm{~cm}^{3}$ and $\left.\mathrm{ER}=0.078 \pm 0.007 \mathrm{~cm}^{3}\right)$. No consistent alterations were observed for both the arithmetic and the harmonic mean thicknesses of the air-blood barrier and for the hematocrit in weanling malnourished rats. However, inasmuch as their $\mathrm{Vc}, \mathrm{Sa}$, and $\mathrm{Sc}$ were lowered, they had a significant reduction in the absolute $\mathrm{DLO}_{2}$. The single large ER group showed higher values for all absolute morphometric parameters when compared with standard ER animals. The differences, however, were not significant, except for Sc (Table 2).

As expected, the growth of the lung parenchyma was more compromised when protein restriction was extended to postnatal d 49, obviously with the most severe effects in the small ER rats (Table 2). All absolute parameters were significantly reduced when compared with age-matched controls. This was associated with a reduction in the arithmetic mean septal thickness by $18 \%$ in ER and by $19 \%$ in DR rats. The harmonic mean air-blood barrier thickness and the hematocrit, however, were unchanged. Evidently, the total $\mathrm{DLO}_{2}$ was decreased in malnourished rats. It also appeared that, in spite of clearly smaller lungs in ER rats, the difference in morphometric parameters to DR animals was mostly not significant, with the exception of Va.

Data of the morphometric lung parameters expressed in relation to body weight (specific results) are presented in Table 4. As described in a companion study (17), the specific lung volumes were increased in protein-restricted rats on d 21 as well as on d 49 when compared with age-matched controls. Regarding lung compartments, $\mathrm{Va} / \mathrm{W}$ generally varied in proportion to the specific volume of the whole lung. A similar trend was apparent for $\mathrm{Vt} / \mathrm{W}, \mathrm{Sa} / \mathrm{W}$, and $\mathrm{Sc} / \mathrm{W}$, but only $\mathrm{Sa} / \mathrm{W}$ on d 49 was significantly augmented versus the control value. However, the $\mathrm{DLO}_{2} / \mathrm{W}$ was unaltered within the same age group. In the two singular ER groups, $\mathrm{Va} / \mathrm{W}$ was the only lung compartment differing significantly from the normal ER values. Here also this parameter followed closely the difference in

\begin{tabular}{|c|c|c|c|c|c|c|c|c|}
\hline & $V_{V_{p}}$ & $\mathrm{~V}_{\mathrm{Va}}$ & $\mathrm{V}_{\mathrm{Vt}}$ & $\mathrm{V}_{\mathrm{Vc}_{\mathrm{c}}}$ & $\mathrm{V}_{\mathrm{Vs}}$ & $\mathrm{S}_{\mathrm{Va}}$ & $S_{V_{c}}$ & $\mathrm{SV}_{\mathrm{ec}}$ \\
\hline \multicolumn{9}{|l|}{ Day 21} \\
\hline Control (3) & $0.857 \pm 0.009$ & $0.832 \pm 0.011$ & $0.112 \pm 0.010$ & $0.056 \pm 0.002$ & $0.168 \pm 0.011$ & $690.1 \pm 44.6$ & $479.7 \pm 4.5$ & $407.3 \pm 34.6$ \\
\hline ER (4) & $0.852 \pm 0.013$ & $0.838 \pm 0.011$ & $0.111 \pm 0.008$ & $0.051 \pm 0.005$ & $0.162 \pm 0.011$ & $702.0 \pm 66.1$ & $364.2 \pm 44.9$ & $393.3 \pm 99.9$ \\
\hline DR (4) & $0.868 \pm 0.006$ & $0.811 \pm 0.016$ & $0.120 \pm 0.008$ & $0.069 \pm 0.009$ & $0.189 \pm 0.016$ & $742.5 \pm 35.3$ & $522.3 \pm 46.0$ & $520.1 \pm 76.1$ \\
\hline \multicolumn{9}{|l|}{ Day 49} \\
\hline Control (4) & $0.865 \pm 0.003$ & $0.786 \pm 0.017$ & $0.111 \pm 0.010$ & $0.103 \pm 0.007$ & $0.214 \pm 0.017$ & $722.9 \pm 43.0$ & $512.3 \pm 32.1$ & $865.7 \pm 61.4$ \\
\hline ER (3) & $0.869 \pm 0.006$ & $0.804 \pm 0.027$ & $0.108 \pm 0.009$ & $0.089 \pm$ & $0.196 \pm$ & $853.3 \pm 48.7$ & $541.4 \pm 65.7$ & $662.8 \pm 208.6$ \\
\hline DR (4) & $0.863 \pm 0.010$ & $0.812 \pm 0.015$ & $0.102 \pm 0.009$ & $0.086 \pm 0.007$ & $0.188 \pm 0.015$ & $780.2 \pm 48.1$ & $524.4 \pm 57.3$ & $736.4 \pm 124.2$ \\
\hline \multicolumn{9}{|c|}{ Day 126 (77 d of refeeding) } \\
\hline Control (4) & $0.853 \pm 0.004$ & $0.791 \pm 0.017$ & $0.087 \pm 0.011$ & $0.123 \pm 0.009$ & $0.209 \pm 0.017$ & $644.3 \pm 53.0$ & $472.7 \pm 38.8$ & $1227.8 \pm 87.6$ \\
\hline ER (4) & $0.870 \pm$ & $0.812 \pm 0.0$ & $0.088 \pm 0.009$ & $0.100 \pm 0.007$ & $0.188 \pm 0.014$ & $654.4 \pm 70.5$ & $427.1 \pm 50.7$ & $944.5 \pm 89.9$ \\
\hline DR (4) & $0.854 \pm 0.008$ & $0.760 \pm 0.015$ & $0.107 \pm 0.005$ & $0.133 \pm 0.011$ & $0.240 \pm 0.015$ & $818.0 \pm 70.2$ & $522.2 \pm 44.2$ & $1265.8 \pm 69.3$ \\
\hline
\end{tabular}
specific lung volume (Table 4).

Table 1. Densities of the lung parenchyma and of its components

Values are means \pm SEM for $n$ animals in parentheses. 
Table 2. Body weight and absolute lung parameters

\begin{tabular}{|c|c|c|c|c|c|c|c|}
\hline & BW (g) & $V_{L}\left(\mathrm{~cm}^{3}\right)$ & $\mathrm{Va}\left(\mathrm{cm}^{3}\right)$ & $\mathrm{Vt}\left(\mathrm{cm}^{3}\right)$ & $\mathrm{Vc}\left(\mathrm{cm}^{3}\right)$ & $\mathrm{Sa}\left(\mathrm{cm}^{2}\right)$ & $\mathrm{Sc}\left(\mathrm{cm}^{2}\right)$ \\
\hline \multicolumn{8}{|c|}{ Parameters for standard experimental groups } \\
\hline \multicolumn{8}{|l|}{ Day 21} \\
\hline Control (3) & $48.0 \pm 0.7^{*}$ & $2.79 \pm 0.07$ & $1.99 \pm 0.05$ & $0.268 \pm 0.027$ & $0.134 \pm 0.010$ & $1648.0 \pm 94.7$ & $1147.8 \pm 43.5$ \\
\hline ER (4) & $20.3 \pm 0.3 \dagger$ & $1.49 \pm 0.04 \dagger$ & $1.06 \pm 0.04 \dagger$ & $0.142 \pm 0.013 \ddagger$ & $0.065 \pm 0.005 \ddagger$ & $896.6 \pm 102.9 \ddagger$ & $460.8 \pm 55.1 \dagger$ \\
\hline DR (4) & $28.3 \pm 0.5 \ddagger$ & $1.84 \pm 0.05 \ddagger$ & $1.29 \pm 0.04 \ddagger$ & $0.191 \pm 0.016 \ddagger$ & $0.111 \pm 0.017 \ddagger$ & $1186.8 \pm 81.8 \ddagger$ & $839.7 \pm 102.4 \ddagger$ \\
\hline \multicolumn{8}{|l|}{ Day 49} \\
\hline Control (4) & $197.2 \pm 2.1$ & $6.57 \pm 0.12$ & $4.47 \pm 0.16$ & $0.631 \pm 0.054$ & $0.583 \pm 0.036$ & $4106.7 \pm 242.0$ & $2915.1 \pm 200.0$ \\
\hline ER (3) & $80.4 \pm 4.4 \dagger$ & $2.90 \pm 0.20 \dagger$ & $2.03 \pm 0.15 \dagger$ & $0.274 \pm 0.038 \ddagger$ & $0.222 \pm 0.029 \ddagger$ & $2154.8 \pm 220.0 \ddagger$ & $1367.7 \pm 213.4 \ddagger$ \\
\hline DR (4) & $95.3 \pm 2.5 \ddagger$ & $3.80 \pm 0.08 \ddagger$ & $2.66 \pm 0.07 \ddagger$ & $0.334 \pm 0.030 \ddagger$ & $0.282 \pm 0.024 \ddagger$ & $2560.1 \pm 167.2 \ddagger$ & $1717.8 \pm 183.1 \neq$ \\
\hline \multicolumn{8}{|c|}{ Day 126 (77 d of refeeding) } \\
\hline Control (4) & $476 \pm 9$ & $11.94 \pm 0.50$ & $8.05 \pm 0.29$ & $0.890 \pm 0.142$ & $1.257 \pm 0.125$ & $6610.7 \pm 782.7$ & $4853.4 \pm 585.8$ \\
\hline $\mathrm{ER}(4)$ & $360 \pm 14 \dagger$ & $9.63 \pm 0.46 \dagger$ & $6.80 \pm 0.30 \ddagger$ & $0.736 \pm 0.077$ & $0.840 \pm 0.083 \dagger$ & $5487.7 \pm 668.6$ & $3580.8 \pm 472.8$ \\
\hline DR (4) & $453 \pm 16$ & $11.13 \pm 0.04$ & $7.22 \pm 0.15$ & $1.014 \pm 0.045$ & $1.268 \pm 0.110$ & $7778.4 \pm 684.3$ & $4969.1 \pm 446.0$ \\
\hline \multicolumn{8}{|c|}{ Parameters for singular ER groups } \\
\hline Large ER d 21 (3) & $26.3 \pm 0.7 \S$ & $1.64 \pm 0.04 \S$ & $1.17 \pm 0.02$ & $0.188 \pm 0.015$ & $0.090 \pm 0.012$ & $1163.6 \pm 33.6$ & $667.3 \pm 37.9 \S$ \\
\hline Small ER d 49 (3) & $49.2 \pm 2.6 \|$ & $2.32 \pm 0.10 \|$ & $1.63 \pm 0.07 \|$ & $0.178 \pm 0.017 \|$ & $0.142 \pm 0.006 \|$ & $1226.3 \pm 123.0 \|$ & $805.4 \pm 29.0 \|$ \\
\hline
\end{tabular}

* Values are means \pm SEM for $n$ animals in parentheses. BW $=$ body weight.

$\dagger$ Smaller than control and DR groups.

¥Smaller than control group.

$\S$ Greater or $\|$ smaller than standard ER group of corresponding age of above ER groups.

Table 3. Air-blood barrier thicknesses and diffusion capacity of the lung

\begin{tabular}{|c|c|c|c|c|c|}
\hline & \multicolumn{2}{|c|}{ Arithmetic mean thickness } & \multirow{2}{*}{$\begin{array}{l}\text { Harmonic mean } \\
\text { thickness, } \tau_{\mathrm{hb}}(\mu \mathrm{m})\end{array}$} & \multirow{2}{*}{$\begin{array}{c}\mathrm{DLO}_{2} \\
(\mathrm{ml} \mathrm{O} / \mathrm{min} / \mathrm{mmHg})\end{array}$} & \multirow[b]{2}{*}{ Hematocrit } \\
\hline & tissue $(\mu \mathrm{m})$ & septum $(\mu \mathrm{m})$ & & & \\
\hline \multicolumn{6}{|c|}{ Parameters for standard experimental groups } \\
\hline \multicolumn{6}{|l|}{ Day 21} \\
\hline Control (3) & $1.91 \pm 0.13^{*}$ & $4.88 \pm 0.33$ & $0.612 \pm 0.067$ & $0.272 \pm 0.005$ & $0.442 \pm 0.004$ \\
\hline ER (4) & $2.10 \pm 0.06$ & $4.67 \pm 0.24$ & $0.708 \pm 0.027$ & $0.120 \pm 0.011 \uparrow$ & $0.413 \pm 0.024$ \\
\hline $\mathrm{DR}(4)$ & $1.89 \pm 0.09$ & $5.06 \pm 0.20$ & $0.743 \pm 0.024$ & $0.201 \pm 0.025 \ddagger$ & $0.459 \pm 0.009$ \\
\hline \multicolumn{6}{|l|}{ Day 49} \\
\hline Control (4) & $1.80 \pm 0.14$ & $5.91 \pm 0.28$ & $0.680 \pm 0.028$ & $0.977 \pm 0.065$ & $0.548 \pm 0.009$ \\
\hline ER (3) & $1.55 \pm 0.08$ & $4.54 \pm 0.37 \ddagger$ & $0.650 \pm 0.026$ & $0.396 \pm 0.084 \ddagger$ & $0.466 \pm 0.017$ \\
\hline DR (4) & $1.56 \pm 0.06$ & $4.80 \pm 0.15 \ddagger$ & $0.739 \pm 0.047$ & $0.486 \pm 0.065 \ddagger$ & $0.480 \pm 0.051$ \\
\hline \multicolumn{6}{|c|}{ Day 126 ( $77 \mathrm{~d}$ of refeeding) } \\
\hline Control (4) & $1.54 \pm 0.07$ & $6.53 \pm 0.32$ & $0.638 \pm 0.052$ & $1.899 \pm 0.208$ & $0.581 \pm 0.018$ \\
\hline ER (4) & $1.64 \pm 0.10$ & $5.80 \pm 0.20$ & $0.688 \pm 0.059$ & $1.311 \pm 0.136$ & $0.552 \pm 0.013$ \\
\hline DR (4) & $1.63 \pm 0.16$ & $5.99 \pm 0.64$ & $0.677 \pm 0.038$ & $1.926 \pm 0.223$ & $0.550 \pm 0.017$ \\
\hline \multicolumn{6}{|c|}{ Parameters for singular ER rats } \\
\hline Large ER d 21 (3) & $2.06 \pm 0.15$ & $4.80 \pm 0.51$ & $0.777 \pm 0.082$ & $0.148 \pm 0.026$ & $0.374 \pm 0.057$ \\
\hline Small ER d 49 (3) & $1.74 \pm 0.06$ & $5.28 \pm 0.35$ & $0.710 \pm 0.040$ & $0.239 \pm 0.016 \S$ & $0.480 \pm 0.035$ \\
\hline
\end{tabular}

$*$ Values are means \pm SEM for $n$ animals in parentheses.

$\dagger$ Smaller than control and DR group.

$\ddagger$ Smaller than control group.

$\S$ Smaller than standard ER rats of corresponding age of ER groups above.

The morphologic appearance of lungs of protein restricted rats at $\mathrm{d} 21$ was that of mature lungs. However, sifting through the micrographs, there was visually a trend to smaller alveoli in these animals (Fig. 1). At d 49 the interalveolar septa of malnourished animals appeared thinner and elongated (Fig. 2). This was most prominent in the ER groups. In small ER animals there was a tendency for larger air spaces in particular regarding alveolar ducts. In no instance was there evidence of alveolar wall rupture.

Effects of refeeding. Data of the lung parameters after refeeding (d 126) are listed in Tables 1-4. The relative values of the parenchymal parameters remained within the normal range. Hence, because of a marked catch-up in body weight and lung volume, refed rats showed a striking regrowth for absolute and specific lung parameters, accompanied by a restoration of $\mathrm{DLO}_{2}$. DR rats even exhibited a complete recovery in morphometric data (Tables 2 and 4). But, as expected from still lower lung volumes, the absolute parameters of refed ER rats did not quite reach normal values, but only Va and Vc remained significantly decreased. In specific results, the only significant finding was a persistence of a higher $\mathrm{Va} / \mathrm{W}$ in refed ER rats (Table 4).

Regarding morphology, the appearance of the lung parenchyma of previously malnourished rats did not differ from that of age-matched controls.

\section{DISCUSSION}

Although it was to be expected that malnutrition starting during the neonatal period and extended to the seventh postnatal week would affect body and lung size, it was surprising that the inner lung structure was practically unaltered regarding 
Table 4. Specific values of lung parameters

\begin{tabular}{|c|c|c|c|c|c|c|c|}
\hline & $\begin{array}{c}\mathrm{V}_{\mathrm{L}} / \mathrm{W} \\
\left(\mathrm{cm}^{3} / 100 \mathrm{~g}\right)\end{array}$ & $\begin{array}{c}\mathrm{Va} / \mathrm{W} \\
\left(\mathrm{cm}^{3} / 100 \mathrm{~g}\right)\end{array}$ & $\begin{array}{c}V t / W \\
\left(\mathrm{~cm}^{3} / 100 \mathrm{~g}\right) \\
\end{array}$ & $\begin{array}{c}\mathrm{Vc} / \mathrm{W} \\
\left(\mathrm{cm}^{3} / 100 \mathrm{~g}\right)\end{array}$ & $\begin{array}{c}\mathrm{Sa} / \mathrm{W} \\
\left(\mathrm{cm}^{2} / 100 \mathrm{~g}\right)\end{array}$ & $\begin{array}{c}\mathrm{Sc} / \mathrm{W} \\
\left(\mathrm{cm}^{2} / 100 \mathrm{~g}\right)\end{array}$ & $\begin{array}{c}\mathrm{DLO}_{2} / \mathrm{W} \\
(\mathrm{ml} \mathrm{O} 2 / \mathrm{min} / \\
\mathrm{mmHg} / 100 \mathrm{~g})\end{array}$ \\
\hline \multicolumn{8}{|c|}{ Parameters for standard experimental groups } \\
\hline \multicolumn{8}{|c|}{ Day 21} \\
\hline Control (3) & $5.82 \pm 0.12^{*}$ & $4.15 \pm 0.10$ & $0.557 \pm 0.048$ & $0.279 \pm 0.017$ & $3433.1 \pm 167.6$ & $2392.2 \pm 72.6$ & $0.564 \pm 0.003$ \\
\hline ER (4) & $7.33 \pm 0.12 \dagger$ & $5.23 \pm 0.14 \dagger$ & $0.698 \pm 0.067$ & $0.320 \pm 0.029$ & $4418.2 \pm 521.9$ & $2279.2 \pm 303.1$ & $0.587 \pm 0.061$ \\
\hline $\mathrm{DR}(4)$ & $6.50 \pm 0.09 \ddagger$ & $4.57 \pm 0.12 \ddagger$ & $0.674 \pm 0.047$ & $0.390 \pm 0.054$ & $4186.4 \pm 219.5$ & $2955.8 \pm 313.1$ & $0.702 \pm 0.077$ \\
\hline \multicolumn{8}{|l|}{ Day 49} \\
\hline Control (4) & $3.33 \pm 0.07$ & $2.268 \pm 0.086$ & $0.320 \pm 0.026$ & $0.296 \pm 0.017$ & $2082.1 \pm 115.1$ & $1478.1 \pm 98.0$ & $0.495 \pm 0.030$ \\
\hline $\mathrm{ER}(3)$ & $3.60 \pm 0.09 \ddagger$ & $2.51 \pm 0.06 \ddagger$ & $0.339 \pm 0.036$ & $0.277 \pm 0.066$ & $2675.6 \pm 205.3 \ddagger$ & $1700.6 \pm 237.7$ & $0.492 \pm 0.101$ \\
\hline DR (4) & $3.99 \pm 0.04 \S$ & $2.799 \pm 0.060 \S$ & $0.350 \pm 0.030$ & $0.296 \pm 0.024$ & $2687.7 \pm 168.5 \ddagger$ & $1807.4 \pm 201.4$ & $0.510 \pm 0.030$ \\
\hline \multicolumn{8}{|c|}{ Day 126 (77 d of refeeding) } \\
\hline Control (4) & $2.51 \pm 0.10$ & $1.69 \pm 0.07$ & $0.186 \pm 0.026$ & $0.264 \pm 0.024$ & $1382.2 \pm 141.3$ & $1015.0 \pm 106.6$ & $0.398 \pm 0.041$ \\
\hline $\mathrm{ER}(4)$ & $2.67 \pm 0.07$ & $1.89 \pm 0.06 \dagger$ & $0.204 \pm 0.017$ & $0.233 \pm 0.018$ & $1519.8 \pm 155.6$ & $991.1 \pm 110.7$ & $0.362 \pm 0.028$ \\
\hline DR (4) & $2.47 \pm 0.09$ & $1.60 \pm 0.03$ & $0.225 \pm 0.017$ & $0.283 \pm 0.031$ & $1721.2 \pm 159.7$ & $1099.5 \pm 103.7$ & $0.428 \pm 0.053$ \\
\hline \multicolumn{8}{|c|}{ Parameters for singular ER rats } \\
\hline Large ER d 21 (3) & $6.21 \pm 0.05 \|$ & $4.44 \pm 0.08 \|$ & $0.715 \pm 0.017$ & $0.341 \pm 0.042$ & $4418.2 \pm 75.0$ & $2530.0 \pm 90.6$ & $0.559 \pm 0.091$ \\
\hline Small ER d 49 (3) & $4.72 \pm 0.09 \pi$ & $3.32 \pm 0.12 \pi$ & $0.361 \pm 0.020$ & $0.290 \pm 0.023$ & $2481.9 \pm 122.1$ & $1641.6 \pm 43.0$ & $0.487 \pm 0.026$ \\
\hline
\end{tabular}

* Values are means \pm SEM for $n$ animals in parentheses.

$\uparrow$ Greater than control and DR groups.

$\ddagger$ Greater than control group.

$\S$ Greater than control and ER groups.

$\|$ Smaller or I greater than standard ER rats of the corresponding age of ER groups above.

its compartmental proportions. This is clearly indicated by normal values in volume and surface densities (Table 1). Evidently, because of the markedly impaired lung growth, all absolute parameters were drastically reduced. In parallel to these findings, the morphometrically determined pulmonary diffusion capacity was declined. However, in most of these parameters, the reduction was in proportion to body weight with a few exceptions which will have to be discussed. Furthermore, normal refeeding to far from the critical period of massive tissue proliferation was associated with a tremendous regrowth of the lung parenchyma.

Previous studies on the subject had in majority concerned weaned rats, that is animals with more mature, although still growing, lungs. Experiments dealing with suckling rats were only of quite short duration and did not examine the effects of long-term refeeding. So, Das (3) analyzed the lungs of rat pups starved twice on postnatal $\mathrm{d} 1$ and 5 (mother withdrawal for 24 h) and then killed the animals on $\mathrm{d} 7$ or 14 . He observed the most intriguing findings on d 14 where lungs of starved rats still had large alveoli in reduced number and thick alveolar walls with short elastic fibers when compared with agematched controls. The severity of starvation in this model could have permanently blunted the process of alveolization. With a different model of milk restriction (litter size increase to 18 versus eight pups for the first $7 \mathrm{~d}$ ), Franck and Groseclose (25) had previously failed to find any significant histologic or morphometric changes in the rat lung. Using similar litter size enlargement until d 14, Massaro et al. (5) could even conclude from LM morphometry that underfeeding did not alter saccule septation and alveolar size (normal mean chord length and surface to volume ratio for air spaces). Reduction in Sa was thus attributed to an undetermined mechanism not depending on septation. In contrast, they showed that dexamethasoneinjected pups had a permanent inhibition of septation. Our findings in weanling rats from dams fed low protein diets and with a severely impaired lactational performance (17) also indicate that, despite growth retardation, the critical process of maturation of the lung parenchyma was not impaired: the lungs were morphologically mature and functionally (as judged by normal $\mathrm{DLO}_{2} / \mathrm{W}$ ) adapted to the size of the animal. In addition, the impression of smaller alveoli in these lungs compared with controls could even suggest that the subdivision process of the developing air spaces was proceeding independently of the limited growth of the thoracic cage.

Longer duration of protein restriction (up to d 49) enhanced the growth deficit of the lung. But this did not have further effects on the relative values of the parenchymal morphometry. However, in contrast to findings at $\mathrm{d} 21$, there was evidence of thinning and even elongation of the interalveolar septa in malnourished rats (decreased septal thickness; Table 3 and Fig. 2). Such features could be explained by a depletion in connective tissue of these lungs, hence in their elastic recoil pressure, as we previously found using the $\operatorname{DR}$ model $(15,16)$. One could thus wonder whether the increment in specific lung volume and in $\mathrm{Va} / \mathrm{W}$ of malnourished rats was related to lung overdistension upon fixative instillation, as we hypothesized in a companion study (17). If such an overdistension of air spaces were a dominant cause for the rise in lung volumes, then we would expect an increase in $V_{V_{p}}$ and $V_{V a}$ along with a lowered $\mathrm{S}_{\mathrm{Va}}$. This was not observed in the standard experimental groups. In the extremely malnourished singular group of small ER rats at $d 49$, the visual impression of larger air spaces (Fig. $2 d$ ) was supported by a significant increase in the volume to surface ratio of air spaces $(\mathrm{Va} / \mathrm{Sa}=13.5 \pm 0.9 \mathrm{~mm}$ in small ER versus $9.5 \pm 0.9 \mathrm{~mm}$ in $\mathrm{ER}$ ) and a decrease in $\mathrm{S}_{\mathrm{Va}}$. Clearly, the lungs of the small ER animals developed larger terminal air spaces as a consequence of undernutrition, that is, they could suffer from a deficit in septation.

As an alternative to overdistension, the increase in specific lung volume could be explained by a relative preservation of 


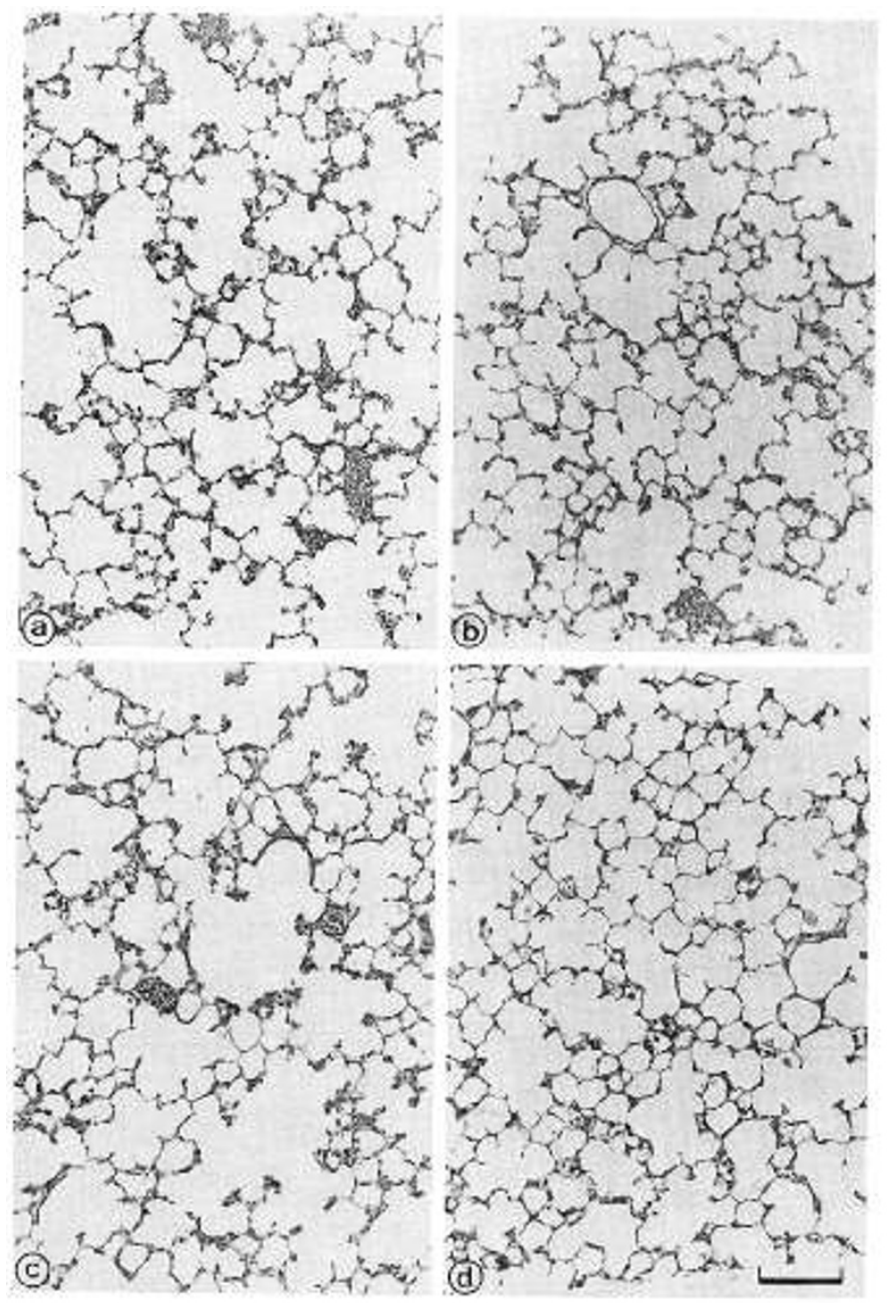

Figure 1. LM photomicrographs of lung parenchyma at $d 21$ ( $\times 150$; bar $=$ $100 \mu \mathrm{m}$ ). $a$, Control group; $b$, DR group; $c$, ER group; and $d$, singular large ER group. The overall aspect of the parenchyma in protein restricted rats is one of mature lung. Their alveoli, however, appear smaller.

lung growth versus body growth during malnutrition. One of us had previously shown an increase in specific lung weight and lung DNA in rats fed a low protein diet from the age of 3 to 7 wk (26). In extremely malnourished adult rats, the increased specific lung weight was proposed to be related to less depletion of lung tissue than of body weight (6). On the opposite side, however, it has been shown, using the DR model, that specific lung weight and lung DNA did not differ from control values (15), and in our present experiment, the rise in $\mathrm{Vt} / \mathrm{W}$ was not statistically conclusive either. Therefore our interpretation of the present findings is that the increased specific lung volume resulted from the addition of small differences in the size of the lung compartments that, taken separately, do not reach the significance level.

One striking finding is the disorganization of the peripheral lung after drastic nutritional deprivation. It has been shown that lungs of severely starved adult rats loosing a significant amount of their initial weight had enlarged terminal air spaces with a disruption of their walls or, in other words, were emphysematous $(2,6)$. Other investigators, however, did not find evidence of alveolar wall rupture in food-restricted rats losing $45 \%$ of their initial body weight and also showing alveolar dilatation

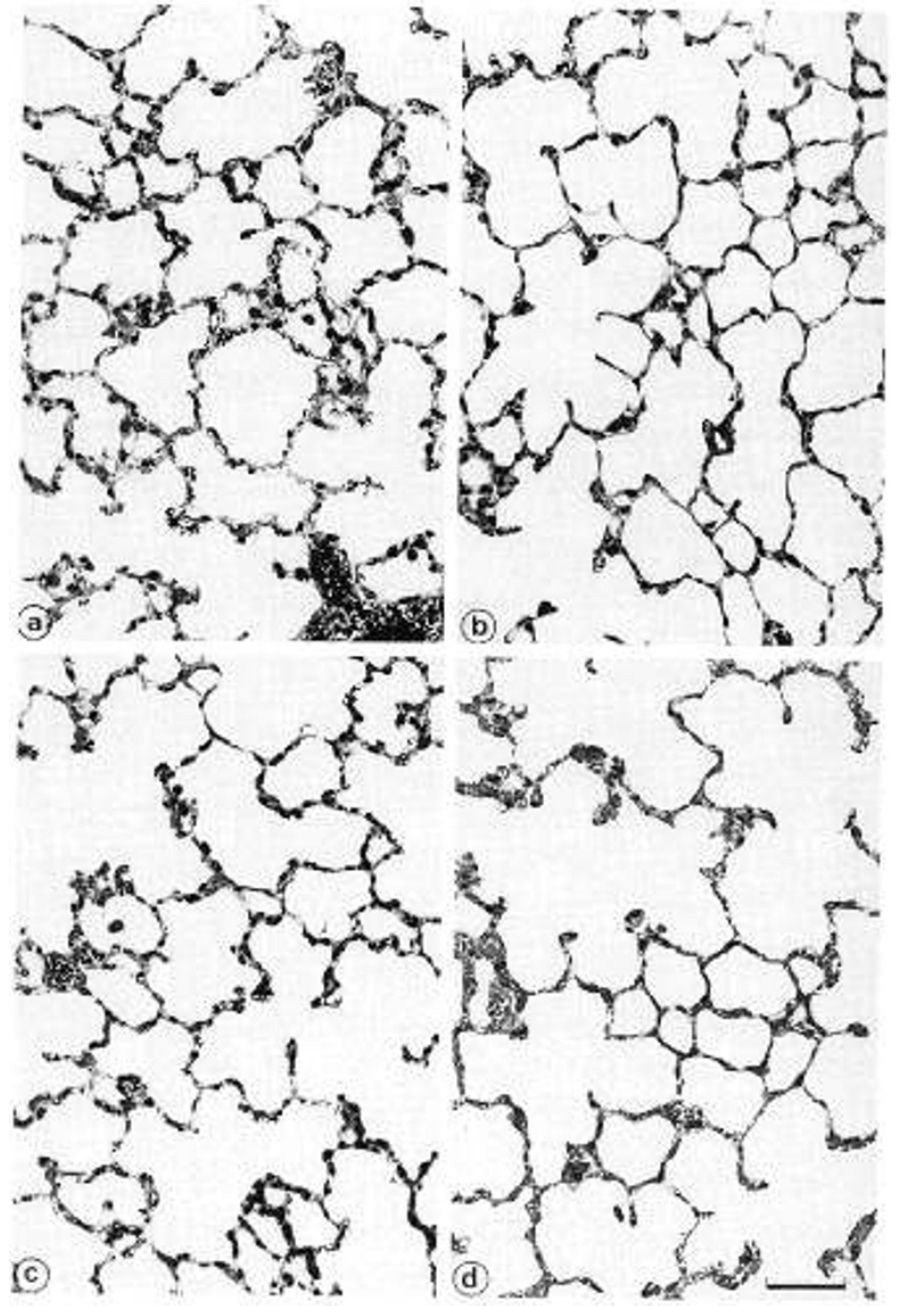

Figure 2. LM photomicrographs of lung parenchyma at d $49(\times 300$; bar $=$ $50 \mu \mathrm{m}) . a$, Control group; $b$, ER group; $c$, DR group, and $d$, singular small ER group. Lungs of protein restricted rats show thinner and elongated interalveolar septa, in particular in both ER groups. In small ER rats, air spaces appear enlarged; alveolar ducts are more prominent

(27). Similarly, Matsui et al. (9) found an inhomogeneous enlargement of alveoli but no destruction of the walls in weanling rats fed an $8 \%$ casein diet ad libitum for $4 \mathrm{wk}$. They concluded that there was no emphysema. It should, however, be mentioned that, during a National Heart, Lung and Blood Institute workshop on Emphysema, it was proposed that experimental animal emphysema could be defined by mere enlargement of terminal air spaces (28). In this study, however, we keep to the definition that emphysema comprises wall disruption. Hence, in our experiments no characteristic emphysema was found in spite of the fact that protein restriction was maintained during the whole period of intensive restructuring of the lung. Whether in previous studies cited above, beside the severity of malnutrition, instillation of the fixative in excised lungs could have aggravated alveolar dilatation and disruption has to be clarified.

The finding of increased $\mathrm{Sa} / \mathrm{W}$ in protein-deficient rats (which in theory are expected to have a decreased $\mathrm{O}_{2}$ consumption) seems to be in contradiction with the well known direct proportional relationship between $\mathrm{Sa}$ and body weight in normal mammalians $(10,29)$. It is, however, easily explained 
by the higher specific lung volumes of our malnourished rats. A rise in specific Sa has also been reported by other authors (5). Interestingly, despite the increase in $\mathrm{Sa} / \mathrm{W}, \mathrm{DLO}_{2} / \mathrm{W}$ was unchanged within groups of similar age.

The refeeding of previously malnourished rats was started at the onset of sexual maturity and was extended to adulthood. During this period and under normal conditions, the rat, especially the male rat, still grows, but at a lower rate than before. Correspondingly, lung growth also slows down (10). Refeeding of our malnourished rats was associated with a striking regrowth of the lung parenchyma, although rats restricted in proteins from birth (ER) still tended to have lower values than controls.

In a study not including morphologic analysis, Sahebjami (30) has reported that weanling rats restricted in food in a manner to loose $25 \%$ of their initial weight could completely recover in lung DNA, lung connective tissue content, and lung mechanics after $15 \mathrm{wk}$ of refeeding. In guinea pigs, in which lung maturation is known to occur earlier than in rats (31), values of lung volume and of parenchymal morphometry were completely restored after food restriction during lactation and subsequent refeeding for 3 wk (7). In adult starved rats, however, air space enlargement was not reversed after 1 wk of refeeding in spite of a complete catch-up for body weight and for lung volume (32). On the one hand, it is obvious that the extent of recovery from lung alterations depends on species and age of the animal, on onset and severity of malnutrition, and on duration of refeeding. On the other hand the manifested capacity for catch-up lung growth raises the question of the structural basis for the quantitative parenchymal recovery. Does it consist of e.g. de novo formation of alveoli, interalveolar wall lengthening, or air space enlargement? To answer these questions, we need to apply more sophisticated methods such as skeletonization (33) and three-dimensional reconstruction (34). The contribution of structural proteins (elastin and collagen) to the parenchymal regrowth also needs to be determined. What has to be retained is that the catch-up growth was of functional benefit, as indicated by the marked increase in $\mathrm{DLO}_{2}$.

We conclude that in our experiments early and moderate protein restriction markedly impaired the growth of the lung parenchyma in the rat, but did not lead to significant changes in the quantitative relationship of the parenchymal compartments. Although we visually detected some minor morphologic changes, the postnatal developmental steps of the parenchyma (i.e. alveolization and microvascular maturation) were not sensibly affected, so that the $\mathrm{O}_{2}$ diffusion capacity of the lung was continuously adapted to body weight. Upon refeeding, the quantitative morphologic recovery was spectacular. Whether the lungs of children suffering from kwashiorkor show a similar pattern of catch-up growth during refeeding remains an important open question.

Acknowledgments. The authors thank B. Haenni, C. Sperantia, K. Babl, M. Hofstetter, and B. Krieger for helpful technical assistance and $\mathrm{E}$. de Peyer for typing the manuscript. We are indebted to Prof. L. Cruz-Orive for judicious advice during methodological implementation of the study and to R. Shepherd for reading our manuscript.

\section{REFERENCES}

1. Sahebjami H, Vassallo CL, Wirman JA 1978 Lung mechanics and ultrastructure in prolonged starvation. Am Rev Respir Dis 117:77-83

2. Sahebjami H, Wirman JA 1981 Emphysema-like changes in the lungs of starved rats. Am Rev Respir Dis 124:619-624

3. Das RM 1984 The effects of intermittent starvation on lung development in suckling rats. Am J Pathol 117:326-332

4. Myers BA, Dubick MA, Gerreits J, Rucker RB, Jackson AC, Reiser KM, Williams SM, Last JA 1983 Protein deficiency: effects on lung mechanics and the accumulation of collagen and elastin in the rat lung. J Nutr 113:2308-2315

5. Massaro D, Teich N, Maxwell S, Massaro GD, Whitney P 1985 Postnatal development of alveoli. Regulation and evidence for a critical period in rats. J Clin Invest 76:1297-1305

6. Kerr JS, Riley DJ, Lanza-Jacoby S, Berg RA, Spilker HC, Yu SY, Edelman NH 1985 Nutritional emphysema in the rat: influence of protein depletion and impaired lung growth. Am Rev Respir Dis 131:644-650

7. Lechner AJ 1985 Perinatal age determines the severity of retarded lung development induced by starvation. Am Rev Respir Dis 131:638-643

8. Karlinsky JB, Goldstein RH, Ojserkis B, Snider GL 1986 Lung mechanics and connective tissue levels in starvation-induced emphysema in hamsters. Am J Physiol 251:R282-R288

9. Matsui R, Thurlbeck WM, Fujita Y, Yu SY, Kida K 1989 Connective tissue, mechanical, and morphometric changes in the lung of weanling rats fed a low protein diet. Pediatr Pulmonol 7:159-166

10. Burri PH, Dbaly J, Weibel ER 1974 The postnatal growth of the rat lung. I. Morphometry. Anat Rec 178:711-730

11. Burri PH 1974 The postnatal growth of the rat lung. III. Morphology. Anat Rec 180:77-98

12. Powell JT, Whitney PL 1980 Postnatal development of rat lung. Changes in lung lectin, elastin, acetylcholinesterase and other enzymes. Biochem J 188:1-8

13. Nardell EA, Brody JS 1982 Determinants of mechanical properties of rat lung during postnatal development. J Appl Physiol 53:140-148

14. Winick M, Noble A 1965 Quantitative changes in DNA, RNA, and protein during prenatal and postnatal growth in the rat. Dev Biol 12:451-466

15. Kalenga M, Henquin JC 1987 Protein deprivation from the neonatal period impairs lung development in the rat. Pediatr Res 21:45-49

16. Kalenga M, Eeckhout Y 1989 Effects of protein deprivation from the neonatal period on lung collagen and elastin in the rat. Pediatr Res 26:125-127

17. Kalenga M, Tschanz SA, Burri PH 1995 Protein deficiency and the growing rat lung. I. Nutritional findings and related lung volume. Pediatr Res 37:783-788

18. Bremgartner MF, Schmid-Steiner AM, Burri PH. Agarzwischeneinbettung für die randomisierte Gewebsentnahme zur gekoppelten licht- und elektronen-mikroskopischen quantitativen Analyse einzelner Lungenlappen. Acta Anat 1983; 117:80

19. Michel RP, Cruz-Orive LM 1988 Application of the Cavalieri principle and vertical sections method to lung: estimation of volume and pleural surface area. J Microsc 150:117-136

20. Cruz-Orive LM, Weibel ER 1981 Sampling design for stereology. I Microsc 122:235-257

21. Humbert D, Cruz-Orive LM, Weibel ER, Gehr P, Burri PH, Hoppeler H 1990 STEPone-an interactive program for manual stereology. Acta Stereol 9:111-124

22. Weibel ER (ed) 1979 Stereological Methods, Vol 1. Practical Methods for Biological Morphometry. Academic Press, London

23. Weibel ER, Federspiel WJ, Fryder-Doffey F, Hsia CCW, König M, Stalder-Navarro, Ruth V 1993 Morphometric model for pulmonary diffusing capacity. I. Membrane diffusing capacity. Respir Physiol 93:125-149

24. Armitage P and Berry G (eds) 1987 Statistical Methods in Medical Research. Blackwell Scientific Publications, London

25. Frank L, Groseclose E 1982 Oxygen toxicity in newborn rats: the adverse effects of undernutrition. J Appl Physiol 55:1248-1255

26. Kalenga M, Henquin JC 1987 Alteration of lung mechanics by protein calorie malnutrition in weaned rats. Respir Physiol 68:29-39

27. Harkema JR, Mauderly JL, Gregory RE, Pickrell JA 1984 A comparison of starvation and elastase models of emphysema in the rat. Am Rev Respir Dis 129:584--591

28. Snider GL, Kleinerman J, Thurlbeck WM, Bengali ZH 1985 The definition of emphysema. A report of a National Heart, Lung, and Blood Institute, division of Lung Diseases Workshop. Am Rev Respir Dis 132:182-185

29. Tenney SM, Remmers JE 1963 Comparative morphology of the mammalian lung: diffusing area. Nature 197:54

30. Sahebjami H 1986 Effects of postnatal starvation and refeeding on rat lungs during adulthood. Am Rev Respir Dis 133:769-772

31. Lechner AJ, Banchero N 1982 Advanced pulmonary development in new-born guinea pigs (Cavia porcellus). Am J Anat 163:235-246

32. Sahebjami H, Vassallo CL 1979 Effects of starvation and refeeding on lung mechanics and morphometry. Am Rev Respir Dis 119:443-451

33. Keller HJ, Burri PH 1981 Automated pattern analysis of growing rat lung. J Microsc 121:119-130

34. Blanco LN, Massaro GD, Massaro D 1989 Alveolar dimensions and number: developmental and hormonal regulation. Am J Physiol 257:L240-L247 